\title{
Histologia do fígado de avestruz (Struthio camelus, Linnaeus 1758)
}

\author{
Histology of ostrich liver (Struthio camelus, Linnaeus 1758)
}

\author{
Gisele SAVIANI ${ }^{1}$; César Garcia Capel WENCESLAU ${ }^{1}$; Roselaine PONSO²; Bruno COGLIATI ${ }^{1}$; Cintia \\ Maria Monteiro de ARAÚJO' ${ }^{1}$; Francisco Javier Hernandez-BLAZQUEZ ${ }^{1}$
}

${ }^{1}$ Faculdade de Medicina Veterinária e Zootecnia da Universidade de São Paulo, São Paulo-SP, Brasil

${ }^{2}$ Faculdade de Zootecnia e Engenharia de Alimentos da Universidade de São Paulo, Pirassununga-SP, Brasil

\begin{abstract}
Resumo
A criação de avestruz (Struthio camelus, Linnaeus 1758) é uma atividade de grande potencial, porém não existem padrões definidos sobre a histologia do seu fígado, que é um órgão de grande importância no metabolismo. O conhecimento de sua histologia pode contribuir para a detecção de doenças e deficiências nutricionais no animal. Para este estudo foram utilizados 24 avestruzes com idades entre 12 e 18 meses (com peso médio em torno de 80 a $100 \mathrm{~kg}$ ), provenientes do abatedouro Don Pig, em Botucatu no estado de São Paulo. Os animais foram abatidos com pistola pneumática e, após a sangria, as amostras do fígado foram processadas e observadas em microscopia de luz e microscopia eletrônica de transmissão (MET). A hematoxilina e eosina (H.E), picrossírius, Gordon e Sweets, Sudan black e o ácido peródico de Schiff (PAS) são colorações usadas respectivamente para observar a morfologia do fígado, colágeno, fibras reticulares, gordura e glicogênio. Foram encontrados os espaços portahepáticos.O glicogênio mostrou média de 5,68\%, o conteúdo lipídico, média de 9,83\%, o colágeno média de 14,71\% e as fibras reticulares média de $5,96 \%$. Quanto à MET notou-se no citoplasma dos hepatócitos, numerosas mitocôndrias, glicogênio, muitas gotas de gordura, alguns lisossomos, retículo endoplasmático granular ao redor das mitocôndrias, algumas células estreladas, célula em degeneração e o canalículo biliar ao centro. Provavelmente o quadro sugestivo de esteatose é resultante do estado nutricional dos animais. Estes resultados demonstraram que os hepatócitos dos avestruzes são muito similares às outras aves, como também muito semelhantes à estrutura e ultraestrutura das células do fígado de mamíferos.
\end{abstract}

Palavras-chave: Avestruzes. Fígado. Esteatose. Glicogênio. Colágeno.

\begin{abstract}
At present the ostrich (Struthio camelus) breeding has been showing a great economical potential, although yet there are not distinct patterns about the histology of its liver, which is an organ of key importance in terms of metabolism. The knowledge of its histology can help the detection of diseases and nutritional deficiencies of this bird. Twenty four ostriches with an average age of 12-18 months and average weight of 80-100 Kg, proceeding from Don Pig Abatteur, located at Botucatu, São Paulo, were used. The birds were slaughtered with and to bleeding. Liver samples were processed for light and electron transmission microscopic studies. Hematoxilin and eosin (HE), picrosirius, Gordon and Sweets, Sudan black and Schiff periodic acid (PAS) were respectively used to observe the liver morphology, collagen, reticular fibers, lipids and glycogen. The liver portal spaces were determined. An average of 5.68\% of glycogen was observed. The lipidic content with an average of $9.83 \%$. Collagen fibers at an average of $14.71 \%$. Reticular fibers with an average of $5.96 \%$. Through transmission electron microscopy we noticed in the hepaticyte cytoplasm the presence of numerous mithocondria, glycogen, several lipidic droplets, some lysosomes, granular endoplasmatic reticulum around the mithocondria, some stellate cells, erythrocytes, nucleus and degenerating cells, besides the central biliary canaliculus. The suggestive steatotic results might result from the animals nutritional status Our results demonstrated that ostrich and other birds hepatocytes are very similar.
\end{abstract}

Keywords: Ostriches. Liver. Steatosis. Glycogen. Collagen.

\section{Introdução}

O avestruz (Struthio camelus, Linnaeus 1758) é a maior ave do mundo. A exploração comercial desta espécie originou-se na África e houve comercialização de matrizes para os Estados Unidos e países da Europa. A criação de avestruzes representa uma im-
Correspondência para:

Faculdade de Medicina Veterinária e Zootecnia da Universidade de São Paulo

Av. Professor Doutor Orlando Marques de Paiva, $n^{\circ} 87$

Cidade Universitária, São Paulo-SP

giselevet@hotmail.com

Recebido: 25/04/2011

Aprovado:18/04/2012 
portante alternativa no setor da agropecuária, tendo em vista seu grande potencial para exploração racional de produtos como carne, couro e plumas ${ }^{1}$. Estudos morfológicos do fígado dos avestruzes são importantes e podem contribuir para o maior aproveitamento zootécnico desta espécie animal, assim como permitir a padronização de parâmetro histomorfométricos que podem ser empregados na inspeção sanitária ou nos exames histopatológico. Algumas características morfológicas do fígado dos avestruzes já foram descritos $^{2}$, porém poucos detalhes são conhecidos. Dessa maneira, este trabalho caracterizou os principais aspectos histológicos e ultra-estruturais do tecido hepático, avaliando o conteúdo dos hepatócitos e os componentes da matriz extracelular.

\section{Material e Método}

Foram utilizados 24 avestruzes (Struthio camelus, Linnaeus 1758) African black, machos ou fêmeas e com idades entre 12 e 18 meses (com peso médio em torno de $87,2 \mathrm{Kg}$ ), provenientes do abatedouro Don Pig, situado próximo à cidade de Botucatu no estado de São Paulo. Fragmentos do fígado foram colhidos e fixados para análises morfológicas em microscopia de luz. Foram fixados em solução de Bouin e incluídos em parafina para análise da morfologia celular pela coloração de hematoxilina-eosina, fibras colágenas (picrossírius) e fibras reticulares (Gordon \& Sweets); fixados em solução ${ }^{3}$ e incluídos em historesina para análise do glicogênio (Ácido Periódio de Schiff - PAS); fixados em solução de formol-cálcio de Baker, pós-fixadas em tetróxido de ósmio e incluídas em historesina para análise do conteúdo lipídico pela (Sudan Black $)^{4}$. As lâminas foram observadas em microscópio de luz (DX 60, Olympus), fotografadas (Axio Can $\mathrm{HRc}$, Zeiss) e a análise morfométrica foi realizada em programa de análise de imagens (Kontron KS 400, Zeiss). A análise da área ocupada pelas fibras colágenas e pelo glicogênio no tecido hepático foi realizada pela mensuração destas estruturas, identificadas pelas colorações específicas, em cinco campos distintos e aleatórios de cada animal $(\mathrm{n}=10)$. A área foi calculada pela somatória das estruturas dos campos analisados em relação à área total, resultando na porcentagem de tecido hepático ocupado pelo colágeno ou glicogênio. A quantificação da área ocupada pelas fibras reticulares e lipídios foi realizada pelo método dos pontos, o qual apresenta uma rede quadriculada com 1369 pontos, formados pela intersecção dos traços horizontais e verticais ${ }^{5}$. Em cada uma das cinco imagens obtidas de maneira aleatória, foi realizada a contagem dos pontos que coincidiam sobre as fibras reticulares ou lipídios, calculando a porcentagem de pontos sobrepostos em relação ao total de pontos. Todos os resultados da morfometria foram representados pelo valor médio e desvio padrão de todos os animais analisados $(\mathrm{n}=10)$.

As amostras de três animais foram fixadas em glutaraldeído $2,5 \%$ tampão fosfato $0,1 \mathrm{M}$, pós fixadas em tetróxido de ósmio a $1 \%$ em tampão fosfato $0,2 \mathrm{M} \mathrm{pH}$ 7,4, desidratados em acetona e incluídos em resina SPURR. Após a confecção dos blocos, estes foram levados ao ultramicrótomo para realização dos cortes semifinos e ultrafinos. Foram realizados cortes semifinos e ultrafinos (50 e $70 \mathrm{~nm}$ ) para visualização em microscópio eletrônico de transmissão.

\section{Resultados}

\section{Descrição Histológica}

O fígado do avestruz é revestido por uma fina cápsula de tecido conjuntivo denso, rico em fibras colágenas. Os espaços porta, contendo ramos da arteríola hepática, ramos da vênula porta-hepática, vasos linfáticos e ductos bilíferos (Figura 1A), e as vênulas hepáticas terminais, vasos linfáticos e ductos bilíferos (Figura 1B) estão distribuídos uniformemente por todo o órgão. $\mathrm{O}$ órgão não apresenta lobos hepáticos definidos (Figura 1B), possui distribuição intersticial 

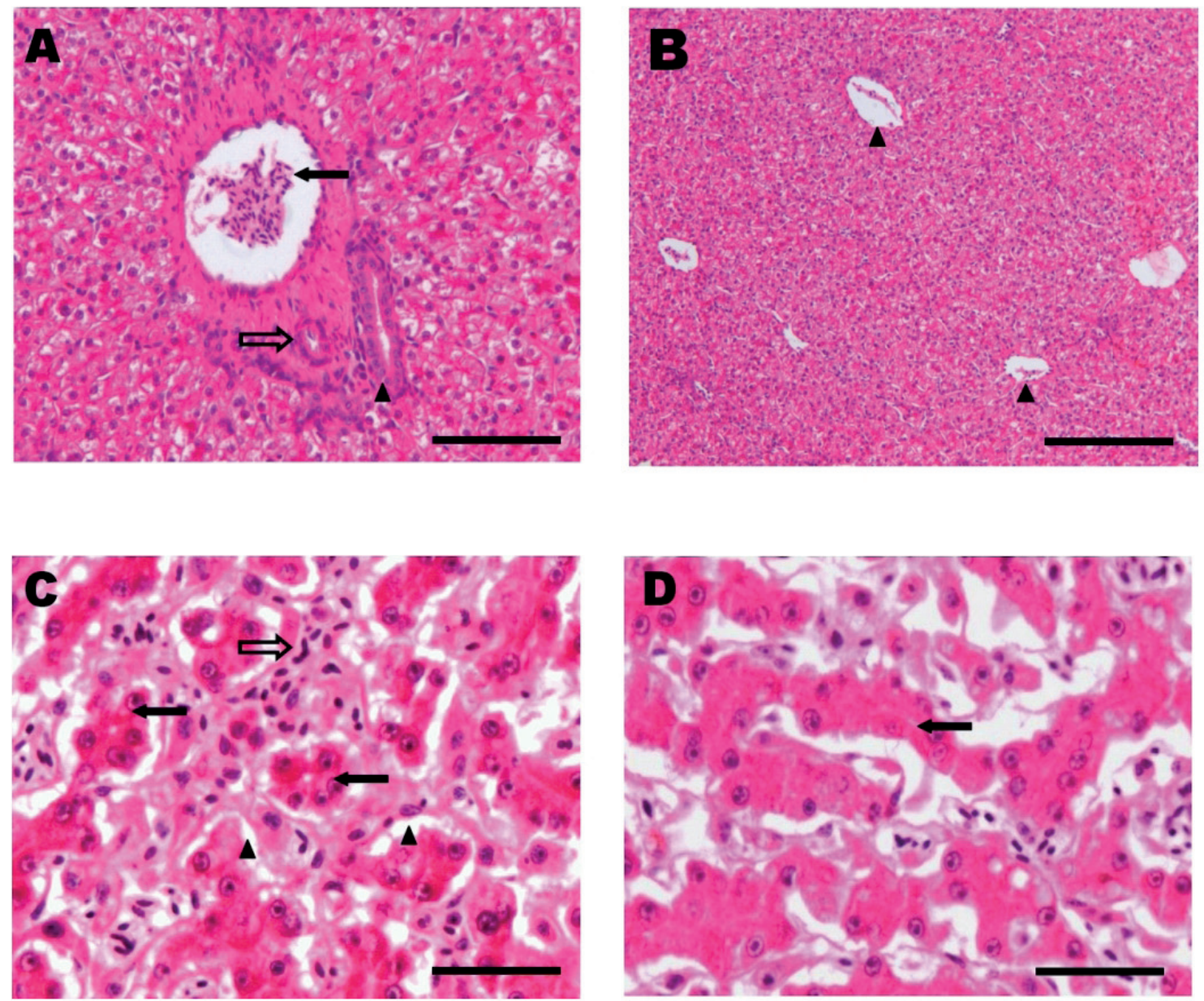

Figura 1 - Fotomicrografia do fígado de avestruz, evidenciando em A: Espaço porta-hepático. Seta cheiavênula porta hepática. Seta vazada indica arteríola hepática. Cabeça de seta indica Ducto biliar. Barra = 200 $\mu \mathrm{m}$; em B - parênquima hepático (ausência de lóbulos hepáticos. Cabeça de seta - vênula hepática terminal. Barra $=300 \mu \mathrm{m}$; em C- parênquima hepático (Seta cheia - trabécula hepática, com canalículo biliar ao centro. Seta vazada - capilar sinusóide contendo hemácias. Cabeça de seta o aspecto esponjoso do citoplasma dos hepatócitos). Barra $=100 \mu \mathrm{m}$; em D - Parênquima hepático. Seta - trabécula hepática com dupla camada de hepatócitos. Barra = $100 \mu$.m. Coloração H.E

de fibras colágenas homogênea e difusa (Figura 2C) na região perissinusoidal e maior concentração nas regiões perivasculares.

O colágeno e as fibras reticulares foram observados, servindo como suporte e estão relacionados com os vasos sanguíneos e com a rede de sinusoides presentes no parênquima hepático (Figuras 2C e 2D). Os hepatócitos, mono ou binucleados, possuem núcleos posicionados centralmente, com cromatina difusa e nucléolos evidentes. Todos os animais analisados apresentaram hepatócitos com aspecto espumoso em maior ou me- nor grau. Este aspecto deve-se à presença de diversas gotículas lipídicas, pois foram positivas após a coloração pela técnica de Sudan Black, específica para lipídios (Figura 2B) e negativas na coloração de PAS.

O fígado do avestruz apresenta duas camadas de hepatócitos nas trabéculas hepáticas, que são definidas como placas de células entre os sinusoides. Observando-se de maneira transversal ao microscópico eletrônico é possível definir o canalículo biliar centralizado, delimitado por hepatócitos e envolto pelos capilares sinusoides do fígado (Figuras 1C e 1D). 

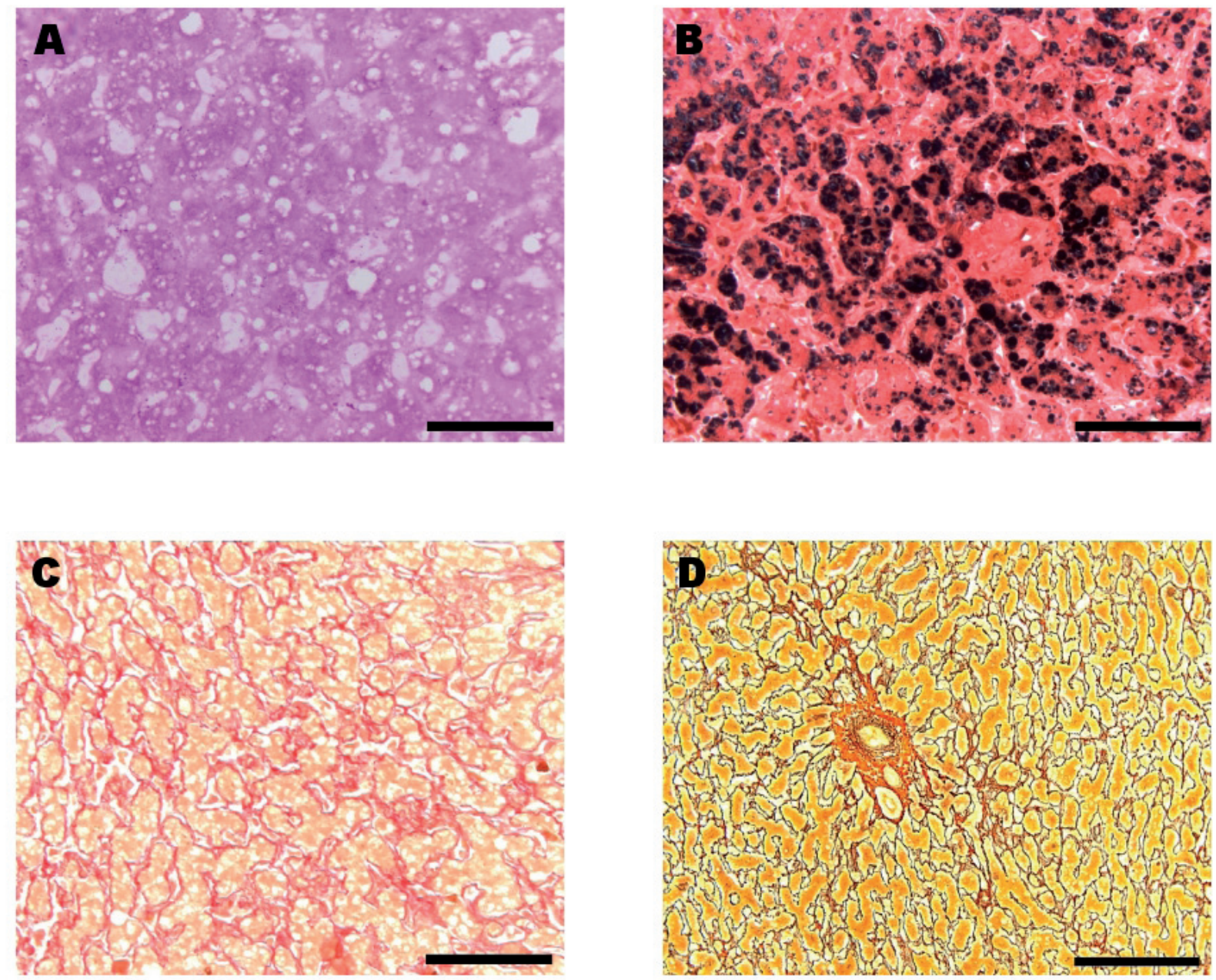

Figura 2 - Fotomicrografia do fígado de avestruz, evidenciando em $\mathbf{A}$ - parênquima hepático com presença de


lipossomos de hepatócitos corados em preto. Coloração Sudan Black B. Barra $=100 \mu \mathrm{m}$; em C- fibras colágenas após diferenciação com ácido clorídrico $0,5 \%$ por 10 segundos. Coloração Picrossírius. Barra $=200 \mu \mathrm{m}$ e em D - espaço porta-hepático. Método de Gordon e Sweets para análise de fibras reticulares. Barra $=200 \mu \mathrm{m}$

\section{Análise e quantificação de glicogênio}

O glicogênio está presente no fígado do avestruz como inclusões citoplasmáticas nos hepatócitos em todo o órgão (Figura 2A). Após a mensuração do glicogênio hepático, verificou-se que alguns animais apresentavam maior quantidade em relação a outros. Os valores das médias e desvios padrões da quantificação de glicogênio de cada animal e da média entre os animais estão expressos na tabela 1 .

Análise e quantificação de gordura intracitoplasmática
Nas técnicas usuais de coloração histológica, foi observado a presença de vacúolos não corados presentes nos hepatócitos de todos os animais e após a coloração positiva destes vacúolos pelo Sudan Black B (Figura 2B), foi possível determinar que tinham conteúdo lipídico as inclusões citoplasmáticas, conferindo um aspecto goticular compatível com um quadro de esteatose hepática. Todos os animais utilizados no projeto apresentavam esta alteração, em maior ou menor intensidade. Foi calculada a média e o desvio padrão dos valores encontrados para a quantidade de 
Tabela 1 - Densidade volumétrica de colágeno, fibras reticulares, glicogênio e lipídios no parênquima hepático, expressos em porcentagem. Ao final, estão presentes os valores médios e seus respectivos desvios padrões dos animais analisados (n=24) - São Paulo - SP, período de 2006 a 2007

\begin{tabular}{|c|c|c|c|c|}
\hline \multirow{2}{*}{ Animais } & \multicolumn{4}{|c|}{ Média dos valores obtidos } \\
\hline & Colágeno & Fibras Reticulares & Glicogênio & Lipídeos \\
\hline 1 & 13,60 & 6,75 & 5,78 & 13,25 \\
\hline 2 & 14,80 & 7,50 & 8,16 & 15,25 \\
\hline 3 & 12,70 & 5,25 & 8,88 & 11,75 \\
\hline 4 & 13,75 & 5,75 & 8,23 & 8,50 \\
\hline 5 & 14,00 & 6,50 & 4,27 & 11,25 \\
\hline 6 & 15,40 & 8,25 & 7,62 & 16,25 \\
\hline 7 & 9,60 & 4,25 & 4,28 & 12,50 \\
\hline 8 & 11,30 & 5,75 & 10,18 & 13,75 \\
\hline 9 & 13,80 & 6,25 & 6,44 & 10,25 \\
\hline 10 & 8,70 & 4,25 & 9,03 & 6,75 \\
\hline 11 & 8,10 & 4,75 & $\mathbf{n} / \mathbf{d}^{*}$ & 12,25 \\
\hline 12 & 10,40 & 6,25 & $\mathbf{n} / \mathbf{d}^{*}$ & 13,75 \\
\hline 13 & 12,10 & 7,50 & $\mathbf{n} / \mathbf{d}^{*}$ & 9,00 \\
\hline 14 & 13,20 & 6,75 & $\mathbf{n} / \mathbf{d}^{*}$ & 10,75 \\
\hline 15 & 18,21 & 6,23 & 6,34 & 4,36 \\
\hline 16 & 15,46 & 4,64 & 4,29 & 3,97 \\
\hline 17 & 17,38 & 5,73 & 4,66 & 10,20 \\
\hline 18 & 15,46 & 4,91 & 4,32 & 9,37 \\
\hline 19 & 14,23 & 6,23 & 5,15 & 4,58 \\
\hline 20 & 24,63 & 6,47 & 2,35 & 6,36 \\
\hline 21 & 16,12 & 5,23 & 4,66 & 9,89 \\
\hline 22 & 21,30 & 5,80 & 4,68 & 9,27 \\
\hline 23 & 18,93 & 5,20 & 2,38 & 5,62 \\
\hline 24 & 19,93 & 6,94 & 1,82 & 7,06 \\
\hline MÉDIA & 14,71 & 5,96 & 5,68 & 9,83 \\
\hline Desvio Padrão & 3,97 & 1,04 & 2,38 & 3,46 \\
\hline
\end{tabular}

n/d* - valor não disponível - impossibilidade de leitura da amostra

gordura no fígado de cada animal, assim como a média e os desvios entre os animais analisados. Os valores encontrados estão representados na tabela 1.

\section{Análise e quantificação de fibras colágenas}

Após a coloração com picrossírius e diferenciação das fibras colágenas do restante do tecido (Figura 2C), foi possível descrever sua localização e quantificar a porcentagem de colágeno hepático, localizado principalmente ao redor dos espaços porta-hepáticos. Foi calculada a média e o desvio padrão dos valores encontrados para a quantidade de colágeno no fígado de cada animal, assim como a média e os desvios entre os animais analisados (Tabela 1).

\section{Análise e quantificação de fibras reticulares no pa- rênquima hepático}

Com a realização do método de Gordon \& Sweets, pode-se visualizar, descrever a localização e quantificar as fibras reticulares presentes no parênquima hepático (Figura 2D), distribuídas uniformemente por todo o fígado do animal. Sua quantidade foi mensurada, calculando-se a porcentagem para cada animal e também a média total de todos os animais (Tabela 1).

\section{Microscopia eletrônica de transmissão ( MET)}

Encontramos numerosas mitocôndrias com vários tamanhos e formatos, sendo esta a organela citoplasmática mais frequente. Algumas cisternas do retículo 
endoplasmático granular estão entre as mitocôndrias e o núcleo. Os lisossomos dos hepatócitos possuem forma em geral arredondada, tamanho e estrutura interna variadas e possuem diâmetro menor que as mitocôndrias. Estes são menores em diâmetro que as mitocôndrias. Os lisossomos podem ser encontrados em qualquer região do citoplasma e possuem uma elevada eletrondensidade. O retículo endoplasmático granular ocorre em todo citoplasma da célula. Encontra-se uma grande quantidade de gotículas de gordura, com forma arredondada, porém, variando no tamanho (Figuras 3A e 3D). Nas figuras 3A e 3D observa-se mitocôndrias (M), lisossomos (Ly), retí- culo endoplasmático granular (REG) na figura 3-A (seta), as gotas de gordura $(\mathrm{Gg})$ nas figuras $3 \mathrm{~B}, 3 \mathrm{C} \mathrm{e}$ $3 \mathrm{D}$, canalículo biliar $(\mathrm{CB})$ e núcleo $(\mathrm{N})$ na figura $3 \mathrm{~A}$. Células estreladas com gotas de gordura no citoplasma (Ce) foram observadas nas figuras 3B e 3C (apenas a célula estrelada), célula em degeneração $(\mathrm{Cd})$ na figura 3B, eritrócitos (E) na figura 3C, colágeno $(\mathrm{C})$ na figura $3 \mathrm{D}$.

\section{Discussão}

A ausência de lóbulos hepáticos no fígado do avestruz é significativa, pois o órgão não se apresenta como ocorre nos mamíferos. As trabéculas hepáticas

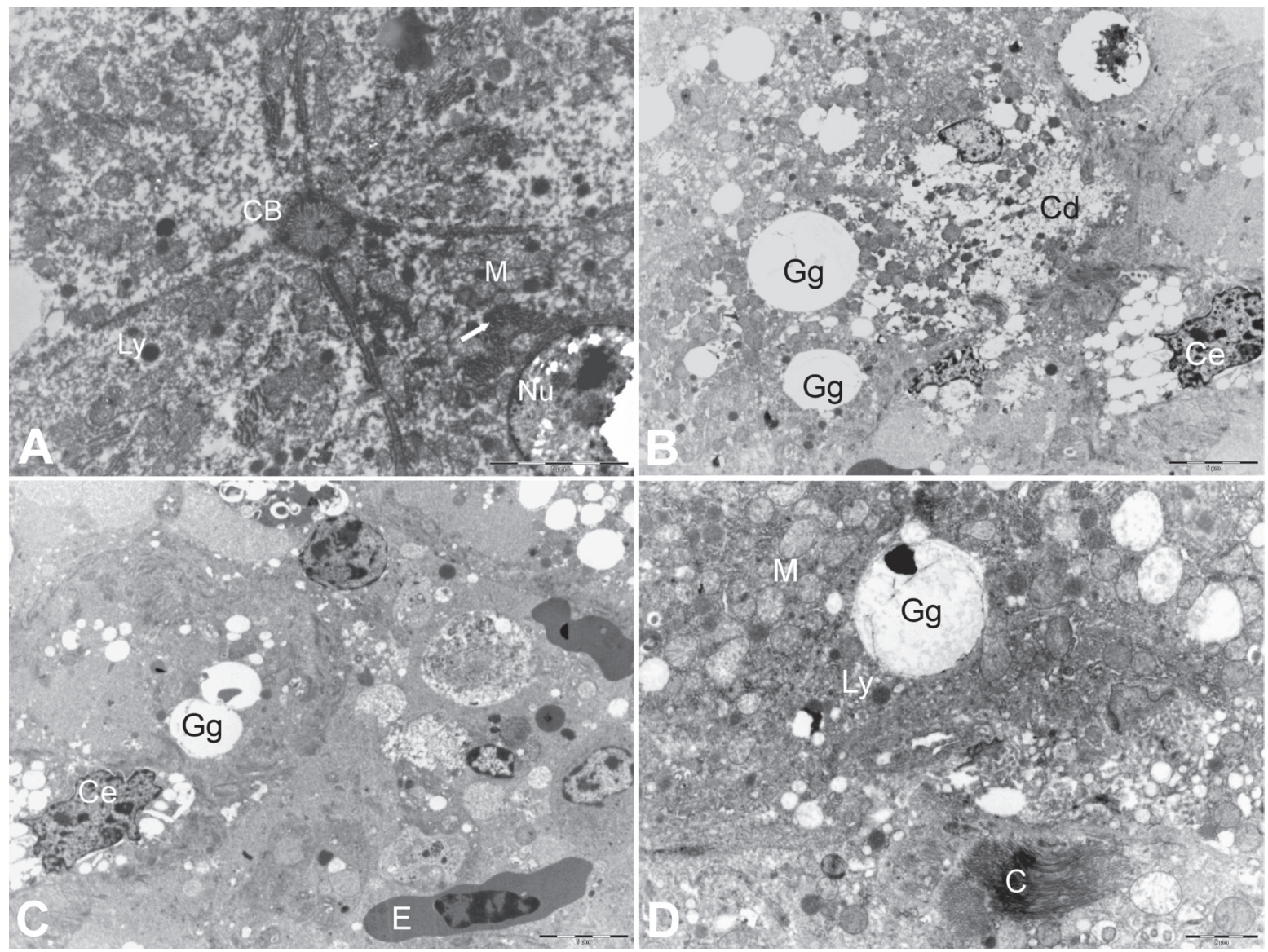

Figura 3 - Eletronmicrografia de lâmina do fígado de Avestruz, evidenciando em A: o canalículo biliar (CB); retículo endoplasmático granular (Seta); Numerosas mitocôndrias $(\mathrm{M})$; núcleo (Nu); lisossomos (Ly); em B: gotas de gordura (Gg); células estreladas com gotas de gordura no citoplasma (Ce); célula em degeneração $(\mathrm{Cd})$; em C: gotas de gordura $(\mathrm{Gg})$; célula estrelada $(\mathrm{Ce})$; eritrócitos $(\mathrm{E})$; em D Eletronmicrografia de lâmina do fígado de Avestruz, evidenciando mitocôndrias (M); gotas de gordura $(\mathrm{Gg})$; lisossomos (Ly) e colágeno $(\mathrm{C}) .5 \mu \mathrm{m}$ 
definidas pelos capilares sinusoides apresentam uma dupla camada de hepatócitos, com o canalículo biliar situado entre as camadas, assim como ocorre em frangos $^{6,78}$ e perus ${ }^{9}$. Porém, o canalículo biliar no caso dos avestruzes estudados costuma localizar-se ao centro.

Nas amostras do fígado de todos os avestruzes coletados, foram encontrados hepatócitos com degeneração macro e microgoticular no citoplasma. A presença destas gotículas de gordura foi evidenciada em MET e foram encontradas em grande quantidade, com forma arredondada, variando no tamanho. Esta presença de lipossomos, conhecida também por lipidose ou esteatose hepática, pode ser decorrente de diversos fatores, desde nutricionais até casos de intoxicações por diversas substâncias ${ }^{10}$. Este quadro é resultante do estado nutricional dos animais, já que nenhum outro aspecto relevante foi encontrado. Como estas aves são destinadas ao abate, sua alimentação é formulada para que os animais apresentem rápido desenvolvimento e alto ganho de peso, com níveis de lipídios acima do necessário, causando uma deposição de micelas de gordura nos hepatócitos. A origem, composição e porcentagem dos ingredientes utilizados na fabricação de dietas podem influenciar de forma bastante significativa para o aparecimento de quadros esteatóticos em aves ${ }^{11}$. O colágeno está distribuído de maneira difusa por todo o órgão. As fibras reticulares se distribuem, formando uma trama juntamente com outras fibras colágenas, contribuindo para a organização estrutural, resistência e consistência do órgão. Como consequência de diversas doenças (incluindo-se a esteatose hepática) que geram lesões celulares no fígado, pode ocorrer o aparecimento de fibrose, podendo evoluir para um quadro cirrótico. $\mathrm{O}$ valor médio da proporção volumétrica de colágeno foi de 12,25\% nos animais analisados e de $6,125 \%$ de fibras reticulares, porém não foram observadas maiores alterações estruturais que pudessem indicar algum tipo de lesão semelhante à cirrose. Não foram encontradas outras informações a respeito da quantidade de colágeno ou fibras reticulares no fíga- do de avestruzes. Nos animais domésticos em geral, o fígado contém cerca de $4 \%$ de colágeno o que pode sugerir que esta ocorrendo uma ligeira fibrose nos avestruzes $^{12}$. O glicogênio, principal forma de armazenamento de carboidratos no organismo, é especialmente metabolizado no fígado. $\mathrm{O}$ valor médio da proporção volumétrica de glicogênio contido nos hepatócitos do fígado dos avestruzes estudados foi de 7,29\%, porém pode-se observar uma grande discrepância dos valores entre os animais, alguns apresentando uma quantidade menor de glicogênio em relação a outros. Esta diferença pode ser consequência de uma série de fatores relacionados ao armazenamento e consumo de energia na forma de carboidratos nos organismos, dentre eles: a condição corporal, estado de saúde, diferenças fisiológicas e de origem genética, stress durante os procedimentos de abate e tempo de jejum pré-abate. Com relação ao número de mitocôndrias hepáticas, nossos achados relacionados aos avestruzes coincidem com os relatados pelos autores ${ }^{7,89}$, que observaram uma grande quantidade e a mesma disposição respectivamente, nas galinhas e perus com tamanhos e formatos heterogêneos, sendo esta a organela citoplasmática mais frequente. Algumas cisternas de retículo endoplasmático granular (REG) estão próximas de algumas mitocôndrias e também estão próximos do núcleo. Hodges ${ }^{7,8}$ e Bhatnagar e Singh ${ }^{9}$ também notaram essas características sobre o REG nas galinhas e perus. Da mesma forma, Stornelli et al. ${ }^{13}$ observaram a presença de REG no citoplasma dos hepatócitos dos avestruzes. Foi constatado que os lisossomos hepáticos, nos avestruzes, possuem uma forma variada no tamanho. Em geral, estes são arredondados na forma e menores em diâmetro em relação ás mitocôndrias e podem ser encontrados em qualquer região do citoplasma. Hodges ${ }^{7,8}$ encontrou lisossomos nas galinhas com essas mesmas características. Bhatnagar e Singh ${ }^{9}$ observaram que os lisossomos nos perus foram distribuídos aleatoriamente. O método utilizado para estimar as porcentagens ou densidades volumétricas de glicogênio, lipídios, colágeno e fibras reticulares 
presentes em todo o fígado, realizado a partir da mensuração de áreas em microscopia foi baseado no Princípio de Delesse, um geologista francês que, em 1842, constatou que a fração volumétrica de minerais poderia ser estimada através da área média na superfície de rochas ${ }^{14}$. Apoiado em provas matemáticas ${ }^{5}$, o princípio de Delesse corrobora com a hipótese de que a área média é também um confiável método de estimação de volume em secções histológicas. A área pode ser diretamente medida, como foi feito no caso do colágeno e glicogênio, ou através do método de contagem de pontos ${ }^{14}$ como se procedeu na contagem de fibras reticulares e lipídios. Esta última opção é utilizada quando o programa de análise de imagem não consegue diferenciar automaticamente a estrutura-alvo do fundo, tendo de ser feito visualmente.

\section{Referências}

1. CARRER, C. C.; KORNFELD, M. E.; ELMÔR, R. A. Origem e histórico. In: CARRER, C. C.; ELMÔR, R. A.; KORNFELD, M. E.; CARVALHO, M. C. A criação do avestruz: guia completo de A a Z. Pirassununga: C.C.Carrer, 2004. p. 13-16.

2.BEZUINDENHOUT, A. J. The topograph of the thoracoabdominal viscera in the ostrich (Struthio camelus, Linnaeus 1758). Onderstepoort. Journal of Veterinary Research, v. 53, n. 2 , p. $111-117,1986$

3. MCDOWELL, E. M.; TRUMP, B. F. Histologic fixatives suitable for diagnostic light and elétron microscopy. Archives of Pathology \& Laboratory Medicine, v. 100, p. 405-414, 1976.

4. BANCROFT, J. D.; STEVENS, A. Theory and practice oh histological techniques. 2. ed. London: Churchill Livingstone, 1982.

5. WEIBEL, E. R.; Stereological methods. San Diego, CA: Academic Press Inc., 1989.v. 1.

6. PURTON, M. D.Structure and ultrastructure of the liver in the domestic fowl, Gallus gallus. Journal of Zoology, London, v. 159 , p. 273-282, 1969.

7.HODGES, R. D. The ultrastructure of the liver parenchyma of immature fowls (Gallus domesticus). Zeitschrift für

\section{Conclusões}

Microscopicamente o fígado do avestruz apresenta; um canalículo biliar ao centro, fibras colágenas e reticulares localizadas ao redor do espaço porta hepático e capilares sinusoides. Assim como a maioria dos animais apresenta numerosas mitocôndrias, alguns lisossomos, algumas cisternas de retículo endoplasmático granular próximas à mitocôndria. Apresenta um aspecto goticular com gotas de gordura em grandes quantidades compatível com um quadro de esteatose hepática, que é provavelmente resultante do estado nutricional dos animais já que nenhum outro aspecto relevante foi encontrado. Os hepatócitos dos avestruzes são muito simulares as outras aves apesar de apesar de também serem muito similares na estrutura das células do fígado de mamíferos.

Zellforschung und mikroskopische Anatomie, v. 133, p. 3546, 1972.

8. HODGES, R. D. The histology of the fowl. London: Academic Press Inc., 1974. p. 88-100.

9.BHATNAGAR, M. K.; SINGH, A. Ultrastructure of turkey hepatocytes. Anatomical Record, v. 202, p. 473-482, 1982.

10.BORDIN, E.L. Diagnóstico post- morten em avicultura: coleta de material e tratamento. São Paulo: Nobel, 1978.

11.DAVAIL, S.; RIDEAU, N.; BERNADET, M. D.; ANDRÉ, J. M.; GUY, G.; HOO- PARIS, R. Effects of dietary fructose on liver steatosis in overfed mule ducks. Hormone and Metabolic Research, v. 37, n. 1, p. 32-35, 2005.

12.BANKS,W. J. Histologia veterinária aplicada. 2. ed. São Paulo: Manole, 1992.

13.STORNELLI, M. R.; RICCIARDI, M. P.; GIANNESSI, E.; COLI, A. Morphological and histological study of the ostrich. Italian Journal of Anatomy and Embryology, v. 1, n. 1, p. 1-7, 2006.

14.AHERNE, W. A.; DUNNIL, M. S. Morphometry. London: Edward Arnold Ltd., 1982. 